\title{
Processos de tomada de consciência e reflexões acerca de valores em jogos de regras de caráter coletivo
}

\author{
Stela Maris Vaucher Farias* \\ Maria Luiza Rheingantz Becker*
}

Resumo: As reflexões apresentadas neste artigo originam-se dos estudos e resultados da pesquisa realizada no Colégio de Aplicação da UFRGS em 2009 e 2010. Este estudo busca investigar a maneira como os estudantes de quinta e sexta séries do Projeto Amora se apropriam dos mecanismos internos dos jogos de regras de caráter coletivo, como isso se dá por meio do processo de "tomada de consciência" (PIAGET, 1974) e quais os desdobramentos em termos da constituição de "valores de troca" e das possibilidades que emergem de um trabalho interdisciplinar. Esta pesquisa está associada ao Programa de Bolsas Primeira Ciência/ UFRGS (2009/2010) e às atividades do projeto de pesquisas Contribuiçôes da Epistemologia Genética para as Práticas Escolares da Faculdade de Educação da UFRGS. Os dados indicam a existência de uma complementaridade entre os processos de constituição de valores dos professores e dos estudantes. A realização de atividades interdisciplinares, no contexto do Projeto Amora, estaria favorecida quando a possibilidade de tornar mais

Professora de Educação Física do Colégio de Aplicação/UFRGS, Mestre em Educação. Pesquisadora da equipe do Projeto de Pesquisa: Contribuições da Epistemologia Genética para as Práticas Escolares. E-mail: stelamaris24@gmail.com

** Psicóloga, Doutora em Educação, Professora de Psicologia da Educação da Faculdade de Educação e do Programa de Pós-Graduação da UFRGS. Coordenadora do Projeto de Pesquisa: Contribuições da Epistemologia Genética para as Práticas Escolares. E-mail: mlbecker@portoweb.com.br 
flexível uma escala de valores fosse exercida intencionalmente. Esse processo contribuiria para a constituição de um trabalho pedagógico organizado, levando em consideração objetos comuns entre diferentes áreas do conhecimento. Constata-se, também, a relevância da utilização de aspectos essenciais do Método Clínico de Jean Piaget.

Palavras-chave: Epistemologia genética; Tomada de consciência; Valores de troca; Interdisciplinaridade; Ensino; Aprendizagem; Interação.

Summary: The reflections presented in this article originate from the studies and results of the research realized at UFRGS's Laboratory School in 2009 and 2010. This study aims to investigate how students from the fifth and sixth grades in the Projeto Amora appropriate the inner workings of collective games with rules, how that happens through the "grasp of consciousness" and which are its unfoldings regarding the constitution of "exchange values" and the possibilities that emerge from an interdisciplinary work. This research is associated to UFRGS's Programa de Bolsas Primeira Ciência (2009/2010) (First Science Scholarshp Program) and to the activities of a College of Education (UFRGS) research project called Contribuições da Epistemologia Genética para as Práticas Escolares (Contributions of the Genetic Epistemology to School Practices). The data indicates a complementarity between the teachers' and the students' processes of constitution of "values". The realization of interdisciplinary activities in the context of Projeto Amora would be favored if the possibility of making a set of values more flexible was intentionally exerted. This process would contribute to the constitution of an organized pedagogical work, taking into consideration common objects between different areas of knowledge. It is also established the relevance of using essential aspects of Jean Piaget's Clinical Method.

Keywords: Genetic epistemology; Grasp of consciousness; Exchange values; Interdisciplinarity; Education; Learning; Interaction. 


\section{Introdução}

O projeto de pesquisa inicial definia como objetivo principal investigar a maneira como os estudantes do Projeto Amora (quinta série/Amora I e sexta série/Amora II) se apropriam dos mecanismos internos dos jogos de regras de caráter coletivo propostos nas aulas de Assessoria de Jogos em 2009. Nessa perspectiva, busca-se verificar de que maneira a "tomada de consciência” (PIAGET, 1977, p. 197-211) participa desse processo e se desdobra em perspectivas morais e possibilidades de constituição dos "valores de troca" por meio das interaçôes estabelecidas nesses contextos.

Vale ressaltar que o Projeto Amora desenvolve suas atividades desde 1995 no Colégio de Aplicação/UFRGS ${ }^{1}$, instituição que procura desenvolver o ensino, a pesquisa e a extensão de maneira integrada, viabilizando experiências inovadoras que têm como objetivo qualificar prioritariamente os contextos educacionais das escolas públicas. Dessa maneira, esse projeto é uma das propostas pedagógicas diferenciadas que, desde o seu início, promove a construção de saberes a partir da inter-relação de abordagens das diferentes áreas do conhecimento. O Projeto Amora constituiu-se por meio de uma reestruturação curricular amparada em uma perspectiva teórica interacionista que leva em consideração os processos de construção de conhecimentos dos estudantes, priorizando a construção de saberes de maneira ampla ao respeitar suas características socioculturais, suas disponibilidades afetivas, seus interesses e suas necessidades. $\mathrm{O}$ referido projeto valoriza a colaboração e a cooperação nos diferentes contextos interativos da ação pedagógica, o que possibilita a instituição de um trabalho efetivamente interdisciplinar. Além disso, uma prerrogativa importante é o valor que é dado à iniciação científica como parte integrante do currículo e a utilização de recursos tecnológicos (TICs - Tecnologias da Informação e Comunicação)

1 Para maiores informações, consulte o endereço: http://paginas.ufrgs.br/projetoamora. 
de maneira integrada desde a sua origem, o que possibilita a constituição de novos contextos interativos entre aprendizes e mestres e acesso, veiculação e transformação de diferentes tipos de informação no cotidiano escolar.

Por meio dessa pesquisa, foi possível delinear possíveis relações entre o contexto educativo do Projeto Amora, as contribuiçốes da Epistemologia Genética [EG] de Jean Piaget e os pontos de vista de alguns autores relacionados à área da Educação Física [EF]. Alguns desses autores coincidem na sua argumentação teórica ao buscar, na referida teoria, argumentos para pensar de maneira mais ampla o que é desenvolvido por essa área do conhecimento, transcendendo a ação pura e simples, trilhando os caminhos do "saber sobre".

Ao pesquisar as produções científicas de EF desde 1992, verificaram-se algumas publicações relevantes para esse estudo em diferentes revistas: Revista da Educação Física da Universidade Estadual de Maringá/PR, Revista Brasileira de Ciência e Movimento da Universidade Católica de Brasília/DF, Revista Movimento da ESEF/UFRGS, Revista Brasileira de Ciência do Esporte (editada pelo Colégio Brasileiro de Ciência do Esporte). No Banco de Teses e Dissertações da CAPES, utilizando os filtros: Epistemologia Genética e Educação Física, foram encontradas sete produções, das quais três teses e quatro dissertações indicam aproximações teóricas.

Na tese de Fogaça (2009), constata-se a utilização de conceitos da Epistemologia Genética acerca de como se constrói a noção de força no mundo físico para investigar a estruturação e a evolução de um conteúdo específico dessa área da Educação Física: a força corporal. Os resultados desse estudo indicam que para compreender a noção de força é necessário constituir um sistema integrado com outras noções, tais como espaço, tempo, velocidade, peso, deslocamento e ultrapassamento. Aponta também para a necessidade docente de analisar de maneira reflexiva e crítica suas concepções epistemológicas. Em uma perspectiva similar, a tese de Saladini (2006) destaca a importância da construção 
e da compreensão da motricidade, apoiando-se na perspectiva interacionista e nos estudos da "tomada de consciência". Para tanto, compara ações pedagógicas diferenciadas - tradicional e construtivista - e a "consciência motora" da ação do chute em dois grupos de crianças de seis a oito anos de idade.

Lisboa (2005), em sua dissertação, procura conceber de que maneira a inteligência atua na solução de problemas no contexto de jogos (pega-pegas). As crianças investigadas demonstram que, em situações de mudança da regra, há um desequilíbrio dos esquemas de ações, o que as leva ao processo de reequilibração, pois as ações incorretas diminuem ao longo do jogo. Além disso, afirma que a inteligência é circunstancial e contextualiza-se na busca da adaptação do sujeito.

Araújo (2003) investiga as relações entre o ensino e a aprendizagem dos jogos da referida área no que tange ao desenvolvimento das estruturas lógicas da inteligência em sua abertura para novas possibilidades do 'pensar sobre'. Nesse intento, a autora parte de uma análise histórica da condição da Educação Física como integrante do contexto escolar que possui uma especificidade por tratar dos temas da 'cultura corporal de movimento', apontando para questões da organização pedagógica da referida área. Defende a ideia de construção e de reelaboração desses conhecimentos por meio de abstrações reflexivas e seus desdobramentos em estruturas lógicas do pensamento.

Farias (2006) investiga a construção da noção espacial como gênese do espaço projetivo, procurando estabelecer relações entre esse processo e o desenvolvimento das interações sociais em jogos de regras de caráter coletivo e jogos de construção (dobraduras). A metodologia adotada utiliza o Método Clínico (PIAGET, 1926; DELVAL, 2002), as 'análises microgenéticas' de Inhelder (1992) e o 'estudo de caso'. Os dados indicam a convergência de processo entre a construção moral e as relações espaço-temporais. A constituição de "valores de troca" (PIAGET, 1973) estaria, assim, no cerne dessa convergência. 
Nessa perspectiva, destacamos alguns outros autores que assumem diretamente ou indiretamente a Epistemologia Genética (EG) como prerrogativa teórica relevante. A escolha desses e não de outros se deve às produtivas relações que esses autores estabelecem com o estudo em questão. Assim, Fonseca (1999, p. 39-50) desenvolve as relações entre o plano das ações e das representaçóes, apontando para a compreensão das razões e finalidades dos diferentes conteúdos desenvolvidos nas aulas e, dessa maneira, garantindo o acesso a tais conhecimentos de maneira criativa, globalizada, cooperativa e prazerosa.

Com a mesma orientação teórica, o artigo de Carracedo e Macedo (2000), O Jogo Carimbador: esquemas de resolução e importância educacional, aponta para o mesmo embasamento teórico e para a construção metodológica que leva em conta grupos etários que se encontram em estágios diferenciados para investigar a maneira como os sujeitos consideram as regras do jogo e os esquemas de resolução de problemas em situações de ataque e defesa. Esse estudo esteve associado ao Laboratório de Psicopedagogia (LaPp) do Instituto de Psicologia da Universidade de São Paulo que enfatiza o construtivismo e a psicopedagogia.

Em Freire (1982; 1991; 1994; 2006; 2009), por sua vez, já se constitui uma referência da abordagem construtivista, desenvolvimentista ou, no entendimento deste artigo, uma concepção interacionista no âmbito da EF. Por meio de suas investigações e de sua produção intelectual, percebe-se a influência teórica de alguns conceitos da Epistemologia Genética para a prática pedagógica da Educação Física. Em sua trajetória inicial de mestrado, Freire (1982) realiza provas operatórias piagetianas relacionadas à seriação, à conservação de peso, a classificações e à conservação das quantidades para selecionar um grupo de quarenta e oito crianças de seis anos e sete meses a catorze anos e um mês que se encontraram nos níveis não-operatório ou intermediário. Esses sujeitos realizaram as outras duas etapas do estudo que consistiam em sessões de atividades físicas e um pós-teste. $\mathrm{O}$ autor traz a [...] "importância da Educação Física [...] pelas ligações que 
ela pode estabelecer entre o sujeito e o mundo real" (FREIRE, 1982, p. 92), além de elaborar reflexões teóricas e práticas acerca das diferentes relações entre a dimensão do 'fazer' e a do 'compreender'. Freire (1991), em sua tese, lança mão de uma análise da motricidade humana para mostrar a coexistência do sensível e do inteligível, argumentando contra os possíveis dualismos que envolvem corpo, mente, alma, espírito, concluindo que o corpo é uma totalidade sistêmica. Desde então, a essência dessas concepçóes reaparecem em suas produções permeadas por novos questionamentos e discussões acerca da realidade da cultura corporal infantil em diferentes nuanças dos jogos e de reflexões acerca da metodologia da educação física.

Em um artigo, Gonzáles (1999) se atém à teoria dos estágios piagetianos para investigar as influências do nível de desenvolvimento cognitivo para a constituição de estratégias de ação em 'jogos motores de situação' que dependem de antecipaçôes para constituírem-se como um pensamento tático. Vale lembrar que, para Piaget (1967), os estágios constituem-se por etapas nas quais o conhecimento tem características peculiares conforme a complexidade das atividades intelectuais. São eles: 1) sensório-motor - no qual as ações são guiadas pela percepção, 2) concreto - inteligência baseada em atividades mentais que se apoiam em representaçôes do real e em um ponto de vista único e 3) formal - quando o pensamento encontra-se focado em proposições verbais e hipóteses. O estágio pré-operatório consiste em um intermediário entre o primeiro e o segundo. Para o referido autor, os estágios desempenham o papel de "instrumento metodológico" de cunho descritivo e explicativo, não sendo tão central como a maioria dos seus leitores costuma supor. Cada estágio traz, no entanto, uma concepção evolutiva de continuidade em distintas formas de equilíbrio das estruturas mentais (MONTANGERO; NAVILLE, 1998) - o que é uma referência para a maioria das pesquisas aqui elencadas.

Gonzáles (2004), anos mais tarde, defende a ideia de que é importante apropriar-se dos elementos essenciais dos jogos 
em sua lógica interna (PARLEBAS, 1988). Dessa maneira, é possível redefinir a maneira de ensinar e treinar, estabelecendo hierarquias entre os conteúdos e escolhendo de maneira mais adequada os procedimentos de ensino. Em uma publicação mais recente para a Secretaria Estadual de Educação do Rio Grande do Sul, Gonzáles e Fraga (2009) auxiliam na elaboração de uma proposta de "referência curricular" destinada à formação continuada de professores da rede ${ }^{2}$, composta de um embasamento teórico destinado aos educadores que se desdobra em uma espécie de livro didático para os estudantes em níveis de escolaridade a partir da quinta série do Ensino Fundamental até o Ensino Médio. Nessa produção, permanecem os esforços de constituir uma metodologia que dê conta da diversidade e complexidade crescentes dos conteúdos, das habilidades e competências da referida área, levando em conta a especificidade do campo no que tange à cultura corporal de movimento - segundo a perspectiva de Soares (1992) e Bracht (1992). No documento para a SEC/RS, a Educação Física integra a área das Linguagens e Códigos, ao lado de Língua Portuguesa, Línguas Estrangeiras, Arte Visual, Dança, Música e Teatro. Os autores adotam uma diretriz metodológica que é pautada pelo respeito às possibilidades de aprendizagem em cada etapa de desenvolvimento, pela sustentação de uma estrutura interna do conhecimento concebido em complexidade crescente e com contextualização. Priorizam, assim como as demais áreas, a prerrogativa de "ler, escrever e resolver problemas" e o trabalho interdisciplinar, dentre outros aspectos. Percebe-se que alguns pressupostos teóricos piagetianos reaparecem nessas produções.

Por meio desses estudos e das leituras realizadas, é possível conceber diferentes trajetórias de inserção da Epistemologia Genética (EG) de Piaget em pesquisas de Educação Física. Ela se mantém viva ao longo dos anos, marcando sua presença em aspectos da metodologia de diferentes áreas do conhecimento,

2 Na referida publicação, a autora participou como leitora crítica. Avaliou a possibilidade de adequação das informações e propostas pedagógicas a realidade e necessidades dos professores da rede pública de ensino no Rio Grande do Sul por possuir experiência em escolas públicas. 
dentre as quais a EF. Alguns autores, mesmo não referindo diretamente a EG como subsídio teórico, explicitam em suas produções alguns conceitos e desdobramentos metodológicos desse referencial.

Por outro lado, algo difícil, mas imprescindível, é situar essa perspectiva teórica no contexto de outros olhares epistemológicos. Muitas são as críticas com relação à inserção da chamada "abordagem desenvolvimentista", baseada na Psicologia do Desenvolvimento e da Aprendizagem, que Bracht (1999b) situa dentro de um quadro de propostas pedagógicas em transformação relacionadas à Educação Física. Esse autor cita as inúmeras tendências desse aspecto, dentre as quais destaca a "psicomotricidade" ou "educação psicomotora” (LE BOULCH, 1986, 1987), que exerceram grande influência na Educação Física brasileira nos anos 70 e 80. Segundo ele, alguns desdobramentos dessa visão ainda repercutem; para tanto, menciona o exemplo do artigo da revista Nova Escola, $A$ Educação Física dá uma mãozinha de Falzetta (1999), no qual, segundo o ele, a EF não evidencia sua especificidade e está subordinada a outras disciplinas do currículo. Nessa perspectiva, o movimento é mero instrumento e as formas culturais do movimentar-se humano são desconsideradas enquanto saber a ser transmitido pela escola. Argumenta que a proposta do professor João Batista Freire (Unicamp), embora preocupada com a cultura especificamente infantil, porque fundamentada também na psicologia do desenvolvimento, possui as mesmas restrições (BRACHT, 1999b).

Acredita-se que as discussões acerca das diferentes abordagens metodológicas devam superar a recorrente busca de delimitação de determinadas orientações teóricas por meio da constituição de um discurso hegemônico no âmbito das discussões da pedagogia da EF. O que se propõe é elaborar perspectivas de interação entre diferentes modos de pensar e, assim, colaborar para o aprofundamento do conhecimento desse campo, auxiliando educadores no processo de ressignificação de sua própria ação docente e na promoção de enriquecimentos 
recíprocos. Propõem-se, para os processos de construção de conhecimentos dos professores em relação ao seu ofício e para os estudantes quanto a sua aprendizagem, uma perspectiva de avanço em termos da superação de uma ação pura e simples em favor de um "saber sobre" ou, como é veiculado na teoria de Piaget, a "tomada de consciência" (PIAGET, 1977, p. 179211) e os seus possíveis desdobramentos em qualquer tipo de abordagem da Educação Física que for escolhida pelo educador em seu contexto de trabalho.

\section{Aspectos Metodológicos}

Esta pesquisa integrou duas perspectivas metodológicas complementares: estudo de caso e método clínico. Dessa maneira, constituiu-se um "estudo de caso" (YIN, 2005) que teve como objetivo ir ao encontro dos processos de construção de conhecimentos dos sujeitos que, em um grupo interativo, evidenciam maior interesse e empenho em apreender os meandros dos jogos propostos, evoluindo em termos dos processos de "tomada de consciência" (PIAGET, 1977). Os estudos de caso são generalizáveis a proposições teóricas e não a populações ou universos. $\mathrm{O}$ seu objetivo "[...] é expandir e generalizar teorias (generalização analítica) e não enumerar frequências (generalização estatística)" (YIN, 2005, p. 30).

Nessa perspectiva, a Epistemologia Genética de Jean Piaget foi eleita para subsidiar as análises de dados. Os pressupostos do Método Clínico (PIAGET, 1926; DELVAL, 2002) serviram de base para a realização da coleta de dados e para o aprimoramento das intervenções realizadas durante as atividades.

É necessário esclarecer que Piaget não dedicou uma produção teórica específica para seu método de pesquisa. As indicações a respeito de sua metodologia devem ser garimpadas ao longo de suas obras. A introdução do livro Representação do mundo na Criança (PIAGET, s/d) evidencia, de maneira agregada, algumas 
premissas metodológicas básicas. Nesse referido livro, o autor destaca a relevância das diferentes representações que as crianças têm a respeito de seu mundo ao longo de seu desenvolvimento. Aponta para a necessidade de o pesquisador compreender essas peculiaridades, assim como as distinções entre a lógica da criança e a lógica adulta. Isso constitui um enorme desafio, que depende da disponibilidade e do empenho do professor no sentido de compreender os processos de construção de conhecimentos dos seus estudantes e a enorme diferença que há em relação a sua maneira de pensar, resultando em um exercício diário de descentração.

Piaget também chama atenção para a importância das "explicações” (PIAGET, s/d, p. 5-12) que as crianças manifestam por meio das suas açôes e representaçôes identificadas na causalidade infantil. Afirma que a "forma" e o "funcionamento" do pensamento da criança podem ser observados quando ela entra em contato com seus pares ou adultos. Por outro lado, o seu "conteúdo" pode ou não ser observado - "[...] É um sistema de crenças íntimas, sendo necessária uma técnica especial para se chegar a sua descoberta. [...]" (PIAGET, 1926, p. 6).

O Método Clínico Piagetiano se destaca por seu caráter construtivo e processual. A observação, a experimentação e a intervenção estão presentes, situando-o em uma perspectiva interacionista e construtivista. Dessa maneira, estuda-se o presente (esquemas procedurais) em função do passado (esquemas prévios) e as possibilidades do futuro (esquemas e estruturas em gênese). É preciso saber observar, procurar algo conforme as categorias eleitas, formular hipóteses e, principalmente, manter-se flexível para reconhecer nas respostas dos sujeitos investigados seus processos de construção de conhecimentos. Além disso, é preciso saber interessar a criança sem fazer sugestões. Segundo Piaget (1926, p. 11),

[...] o bom experimentador deve, efetivamente, reunir duas qualidades muitas vezes incompatíveis: saber observar, ou seja, deixar a criança falar, não desviar nada, não esgotar nada e, ao mesmo tempo, saber buscar algo preciso, ter a cada instante uma hipótese de trabalho. 
Para tanto, foram eleitas duas categorias de análise: os processos de tomada de consciência e os processos de construção de valores de troca. Perguntas norteadoras também foram elaboradas, tais como:

- Como os estudantes se apropriam dos mecanismos internos dos jogos propostos?

- De que maneira o processo de 'tomada de consciência' participa e se desdobra em possibilidades de constituição dos valores de troca na interação em jogos de caráter coletivo durante os momentos das intervenções e entrevistas?

- Qual a relevância desta proposta no contexto das discussões acerca da metodologia da Educação Física?

Esta pesquisa, ao acolher essas duas perspectivas metodológicas complementares (estudo de caso e método clínico), reafirma, de certa maneira, a relevância das mesmas ao constituírem um método de pesquisa que se prolonga em possibilidades de qualificação do processo de ensino e de aprendizagem que ocorre nas aulas de Educação Física. Essa investigação valoriza, assim, o que pode ser construído nas trocas entre o que os estudantes sabem e vivem da cultura corporal e as possíveis relaçóes estabelecidas por eles em função do que ocorre no espaço da aula por meio da interação com seus professores.

Nessa perspectiva, os pressupostos básicos do Método Clínico (PIAGET, s/d 1926; DELVAL, 2002) podem contribuir para aprimorar a maneira como os professores interagem com seus estudantes, tornando-os mais coerentes e sensíveis para fazer escolhas acerca do que é necessário dizer ou calar no momento do jogo, intervir ou aguardar em situações de conflito, selecionar ou descartar em termos de conteúdos e de recursos materiais, por exemplo. A Epistemologia Genética, por sua vez, pode auxiliar na compreensão dos processos de apropriação do espaço, na coordenação de ações e de representações e, de maneira mais ampla, possibilitar a descentração, ou seja, a saída da exclusividade de um ponto de vista próprio em prol do estabelecimento de um 
conjunto de relaçôes por meio do qual diferentes perspectivas podem ser coordenadas. Dessa maneira, menos egocentrismo e mais cooperação podem ser instituídos nas interações que ocorrem no contexto da EF.

Assim, as aulas de Assessorias do Projeto Amora foram escolhidas para constituir o espaço da pesquisa. Foi criada, então, a Assessoria de Jogos com a participação de dois professores das turmas de quinta e sexta séries, um de Teatro e outro de Educação Física. A ideia inicial era focar somente nos processos de construção de conhecimentos e apropriações de ações e representações inerentes aos jogos do contexto da Educação Física. No entanto, o jogar também faz parte da realidade de trabalho educativo da área de Teatro, e alguns conceitos, habilidades e conteúdos são comuns ao trabalho docente de ambas as áreas e, no Projeto Amora, realiza-se habitualmente diversas atividades integradas, porque interdisciplinares. Iniciou-se, assim, um longo e produtivo processo de estabelecimento de relações e de colaboração mútua entre as duas áreas do conhecimento, mesmo que o interesse inicial não fosse abordar a questão da interdisciplinaridade. $\mathrm{O}$ foco, no entanto, continuou sendo o desenrolar das aprendizagens e as possíveis apropriações de ações de estudantes em interação durante os jogos propostos. Assim, foram organizadas sessões em que aconteceram os jogos coletivos e individuais do contexto da Educação Física e do Teatro propostos para a realização do estudo, que foram fotografadas pela professora e por (inter)juízes (os próprios estudantes).

Nessa perspectiva, ao elencar, para as sessões previstas na metodologia, um jogo da Educação Física em sua lógica própria, verificou-se um jogo equivalente do Teatro. A lógica interna dos referidos jogos eram respeitadas e os estudantes eram provocados a compreendê-la, assim como as suas peculiaridades, por meio de intervenções verbais nos intervalos das jogadas, das questões propostas para os registros escritos e das propostas de desenhos realizadas logo após a prática. Todos os dados obtidos foram transcritos e organizados. Esse trabalho contou com a participação 
de bolsistas do Ensino Médio ${ }^{3}$ que participaram do Programa Primeira Ciência/UFRGS desenvolvido no Colégio de Aplicação nos anos de 2009 e 2010.

Por meio da observação acerca do modo como se desenrolaram as interações durante os jogos de regras da Educação Física (EF) e do Teatro (T), foi possível verificar os processos de apropriação de seus elementos fundamentais: conhecimento das regras e do espaço, coordenação estratégica, aspectos sociais e de cooperação e as diferenciaçôes entre o corpo em estado de representação do Teatro e o corpo em ação e reflexão da Educação Física. Os envolvidos foram desafiados a mobilizar ações, representações e esquemas por meio da construção de algumas possibilidades de troca permeadas por regras constituídas em conjunto.

Como já foi mencionado anteriormente, nessa Assessoria foram desenvolvidos diferentes tipos de jogos, selecionados a partir das características de sua lógica interna (PARLEBAS, 1988) que interessavam à pesquisa. Assim, foram escolhidos prioritariamente jogos em que há interação com o adversário: pique-bola, softball (EF), jogo do pirata e suas variaçôes $(\mathrm{T})$, e outros sem interação com o adversário: carrinhos, labirinto (EF) e mímica $(\mathrm{T})$.

No ano de 2009, as assessorias foram compostas por quatro grupos $(\mathrm{A}, \mathrm{B}, \mathrm{C}, \mathrm{D}$,$) com aproximadamente vinte estudantes da$ quinta e sexta séries do Ensino Fundamental. A organização dos mesmos seguiu o critério de composição que sempre é adotado no Projeto Amora: o tipo de apoio pedagógico que se faz necessário no momento em que se encontra cada estudante. Dessa maneira, existem grupos constituídos para desenvolver competências e habilidades relativas à leitura è è escritura, outros necessitam de um trabalho mais efetivo em termos de raciocínio lógico e um grupo pode se estruturar com o objetivo de desenvolver suas

3 Bolsistas que trabalharam nesta pesquisa: Diuliano Wagner dos Santos (2009) e Mateus Miranda Ribeiro (2009 - bolsista voluntário), Lucas Eduardo Ebbesen Silva (2010) e Richele Moreira Schwartzhaupt (2010). 
aprendizagens de maneira mais aprofundada, buscando alcançar patamares de complexidade crescente.

Todos os grupos participaram da Assessoria de Jogos e realizaram a dinâmica constituída para a metodologia da pesquisa: enquanto realizavam o jogo eram fotografados e, no intervalo das partidas, organizavam-se momentos de bate-papo. Nesse contexto, eram feitas perguntas pelos professores e pelos estudantes, as principais ideias eram anotadas no bloco de campo. Ao final das sessões, optava-se por realizar um registro escrito com perguntas desencadeadoras, realizar desenhos alusivos aos momentos importantes ou projetar as fotos e elaborar novas perguntas, que eram respondidas e registradas, seguindo as perspectivas do método clínico apontadas anteriormente.

Ao longo de um mês aproximadamente, os referidos grupos foram observados e foi feita a escolha de um deles para o aprofundamento da investigação. $\mathrm{O}$ critério adotado foi o grupo que continha o maior número de estudantes interessados e engajados na proposta metodológica e na apropriação dos jogos eleitos. Após a escolha, alguns estudantes foram também convidados para entrevistas particulares e motivados, assim como os demais, a realizar outras atividades: atuarem como fotógrafos, pensarem em estratégias variantes e novidades para os jogos. Essa dinâmica metodológica é rica em possibilidades. Foram definidos, ao longo do estudo, os momentos de $A$ ção $(A$.), nos quais foram realizadas as atividades propostas, e outros momentos de Possibilidade de Apropriação das Ações (P.A.A.) por meio dos quais os processos reflexivos se ampliaram, rompendo com o imediatismo do êxito da ação e evoluindo em termos de entendimento e complexidade.

Por meio do levantamento feito acerca dos trabalhos científicos já realizados na Educação Física, no que concerne aos pressupostos da Epistemologia Genética, verifica-se que isso não é uma novidade, pois esse tipo de método já foi apontado na maioria dos estudos citados anteriormente. Entretanto, é curioso que ainda se constitua num desafio torná-lo parte integrante da prática metodológica da Educação Física sem o temor de estar 
perdendo tempo da prática ou mesmo servindo a outras áreas do conbecimento. Acredita-se que o professor deva ter consciência de seu trabalho docente em termos da especificidade da função pedagógica no referido campo, dentro da multiplicidade de saberes na escola. No entanto, a experiência docente no Projeto Amora comprova, e o estudo em questão ratifica que, quando os professores estão dispostos a partilhar os saberes com competência, coerência e humildade, o próprio campo se fortalece e aprendizagens cada vez mais significativas ocorrem.

\section{Tomada de Consciência}

O conceito da 'tomada de consciência' (PIAGET, 1977, p. 179-211) é central para as discussões que estão sendo elaboradas. No senso comum, pode-se dizer que ela acontece quando cain a ficha para os mais antigos, ou quando me liguei para as novas gerações. Teoricamente a tomada de consciência pode ser definida como uma apropriação gradual das ações do sujeito, em um movimento possível de saída da Periferia do Objeto e do Sujeito em direção à sua Centralidade.

A Periferia refere-se aos aspectos figurativos e perceptivos, que são, por assim dizer, os estados do que se quer aprender, traduzidos por imagens mentais. Como exemplo, pode-se pensar na representação desprovida de detalhamento que se tem do espaço quando se aprende um jogo ou o conhecimento incipiente de suas regras que não proporciona o entendimento de todas as relações que compõem a dinamicidade do jogo. Centralidade refere-se à dimensão operativa que pressupốe a transcendência dos aspectos citados anteriormente em prol da constituição de ações interiorizadas reversíveis que possibilitam coordenações em estruturas mais complexas compondo sistemas. Como ilustração pode-se imaginar a situação de um jogador experiente que conhece os mecanismos internos e utiliza adequadamente o espaço de jogo para pensar e colocar em prática uma ação ofensiva ou 
defensiva, uma estratégia ou um sistema de jogo. A saída de $P$ para $C$ não é fácil e não se dá ao acaso, porque depende de um árduo processo de (re)construção que pressupõe a atividade, o interesse e o empenho do sujeito.

A construção dos conhecimentos na Educação Física depende das aprendizagens corporais anteriormente construídas (esquemas prévios), das possibilidades de cada estágio de desenvolvimento e das interaçôes que o sujeito estabelece entre seu próprio corpo (como um objeto) e o espaço circundante, os objetos na prática das atividades físicas (bola e demais materiais), os outros sujeitos envolvidos e, também, o adulto que realiza a mediação no processo de construção das aprendizagens. Dessa maneira, todas as novas aquisiçôes em termos de conhecimento na área estão intimamente relacionadas às possibilidades atuais e ao que pode vir a ser. As tomadas de consciência seguem essa mesma perspectiva.

O estudante avança na medida em que mobiliza e reorganiza esquemas anteriormente construídos para dar conta do novo. Como já foi mencionado, a tomada de consciência procede da Periferia (uma zona indiferenciada entre o sujeito e o objeto), parte da busca de um determinado objetivo (que nas aulas de Educação Física são os fins dos jogos) e depende das organizações realizadas pelo sujeito: seus movimentos no espaço de jogo, o tipo de manipulação do objeto envolvido na atividade, as trajetórias, que devem ser realizadas pelos corpos e pelos objetos no espaço, e a hipótese, de difícil aceitação, que é compartilhar um objeto - a bola, por exemplo. Quando a criança atenta para essas possibilidades, ou seja, para os meandros do próprio jogo, consegue desvincular-se do êxito puro e simples da ação e da perspectiva egocêntrica.

A “tomada de consciência” é possível na medida em que se apoia em ações realizadas e antecipações, em vislumbres de possibilidades. Essas antecipações oferecem ao sujeito caminhos para "[...] empenhar-se a seguir na direção da natureza intrínseca das coisas, e de suas conexốes causais” (PIAGET, 1977, p. 204), 
na busca dos meios necessários que não estão explícitos no objeto, nem em imagens mentais, mas que dependem de coordenações de ações não observáveis. Esse mecanismo coordenador do sujeito abre portas para um universo de abstrações.

Isso tudo diz respeito à maneira como os diferentes níveis e as perspectivas de reflexão se constituem no desenvolvimento da inteligência. Esse processo apresenta, por sua vez, uma espécie de regularidade na construção das categorias da razão (estruturas casuais, espaço-temporais e objeto permanente), ou seja, apesar de todas as noções constituírem-se por meio da ação, elas são profundamente transformadas e ressignificadas conforme os graus de conceituação alcançados. Nessa perspectiva, há uma longa distância entre a ação e a compreensão desse fazer. A tomada de consciência constitui um processo que não é dado, mas construído. Esse processo se dá por 'regulações ativas' (PIAGET, 1977, p. 13-19) que estão relacionadas às possibilidades de cada fase de desenvolvimento, permitindo que o sujeito coordene a sua ação em função de uma 'escolha', promovendo, dessa maneira, a superação do caráter automático que regula determinadas ações ou situações. Tal superação depende das 'coordenações ativas' (ibid., p. 207) estabelecidas pelo sujeito em sua interação e, também, do caráter operatório centrado nas modificações da ação. Todo esse processo descrito está intimamente relacionado às questôes morais.

\section{Valores na acepção piagetiana, a perspectiva moral e o que ocorre na Educação Física}

Analisar como os estudantes constroem conhecimentos e de que maneira é possível conceber tais processos nos encaminha para inúmeras possibilidades. Aqui se propõe adotar algumas ideias da perspectiva interacionista piagetiana. Esta pesquisa partiu do princípio de que há uma implicação recíproca entre o mecanismo 
de constituição de valores e a maneira como os estudantes elaboram suas interações sociais, havendo, fundamentalmente, uma indissociabilidade dessas em relação às questões da construção da noção espacial, por exemplo. Todo o tipo de avanço em termos de apropriação do espaço de jogo pode estar acompanhado por condutas mais colaborativas e descentradas nas interações que são estabelecidas nesse contexto.

Tudo o que ocorre na escola e, por conseguinte, na EF, depende das trocas que ocorrem entre os sujeitos que interagem e constroem conhecimento. Na obra Estudos Sociológicos, Piaget (1973, p. 7) afirma que a "coordenação geral das ações" fundamenta as operações intelectuais e também intervém em uma troca interindividual.

Segundo Piaget (1973), há um paralelismo entre os "fatos mentais" e os "fatos sociais". Os primeiros são constituídos por três aspectos distintos, mas indissociáveis, expressos em qualquer conduta: o aspecto cognitivo, o aspecto afetivo e o sistema de indices ou símbolos. Já os "fatos sociais" remetem aos três aspectos presentes nas relações interindividuais: regras (como obrigação imanente), os valores coletivos (que implicam elemento de troca interindividual) e os sinais convencionais (convenções). Na referida obra, o autor procura, por meio da psicologia genética e da sociologia, investigar aspectos da vida social que podem ser considerados comuns, estruturas mais ou menos complexas e diferentes níveis de equilíbrio para compreender a dialética das contribuições das diferentes áreas do conhecimento amparadas por pesquisas empíricas. As perspectivas interdisciplinares não ocorrem senão por meio de um sistema de regulações e de equilibrações, o que descarta o acontecimento aleatório, a inexistência de estruturação ou a programação preestabelecida.

O regramento social, segundo o referido autor, depende de uma perspectiva cognitiva individual que o estrutura - essa estruturação possibilita as coordenações de ações e a cooperação entre os sujeitos. Por outro lado, de forma indissociável, a própria construção de conhecimentos depende da interação social para se 
estruturar. O sujeito constitui, em sua ação individual, um aspecto normativo que expressa eficácia e um equilíbrio adaptativo. Da mesma maneira, é possível conceber, em uma relação dual, essa mesma coerência do pensamento individual quando o sujeito colabora com o outro.

Piaget define valor como o conjunto de sentimentos projetados no objeto, um caráter afetivo, que na acepção do autor significa interesse, disponibilidade ativa direcionada para algo e que pode ou não ser passível de troca. O sujeito elabora para si alguns valores que são determinados por sua afetividade. Vale reiterar que essa palavra está relacionada ao interesse e à energia despendida e regulada em toda a conduta. Piaget estudou a maneira como se configuram esses valores em escalas nas diferentes instâncias do desenvolvimento: desde as primeiras trocas do bebê até os mais elevados valores coletivos.

Os valores são passíveis de formar uma consistência social. Quando isso ocorre, eles tornam-se dependentes de "um sistema total de relações entre dois ou vários sujeitos, por um lado, e os objetos, por outro" (PIAGET, 1973, p. 38).

A possibilidade de construir valores ${ }^{4}$ em comum está relacionada ao surgimento da função semiótica, a qual confere a durabilidade necessária aos mesmos, surgindo o que Piaget denomina de "valores virtuais" (ibid., p. 124) - quando a essência ou cerne do que foi valorado permanece e se instaura como representação, suscitando novas construções. Relembrando o que foi discutido em termos da passagem de $P$ (periferia) para $C$ (centralidade) em processos de 'tomada de consciência', a construção dos 'valores de troca' também é parte integrante de um processo mais geral de transcendência de uma assimilação prática, ou seja, de um interagir que não leva em consideração o ponto de vista do outro e que, apesar de coordenar ações práticas e representativas, ainda está profundamente relacionada

$4 \quad$ PIAGET (1973) admite para o sistema de trocas a mesma lógica das proposições; para tanto, existem valores reais: $r$ (valor ou serviço prestado) e $s$ (satisfação) e também valores virtuais: $t$ (dívida) e $v$ (crédito). 
às perspectivas ou interesses particulares do sujeito. Por outro lado, a perspectiva de assimilação por meio de conceitos na interação social estaria relacionada à construção desses valores estando intrinsecamente relacionada à constituição de uma perspectiva projetiva e, portanto, à possibilidade de saída do egocentrismo, estabelecendo, dessa maneira, uma condição para a conservação, mobilidade e veiculação desses valores no grupo. Para Piaget, a interação social ocorre

[...] em todos os lugares em que se apresentem as relaçóes de sujeito a objeto, e é o caso da sociologia como em outros campos, mesmo e principalmente se o sujeito é um "nós" e que o objeto é o de vários sujeitos ao mesmo tempo, o conhecimento não parte nem do sujeito nem do objeto, mas da interação indissociável entre eles, para avançar daí na dupla direção de uma exteriorização objetivante e de uma interiorização reflexiva (PIAGET, 1973, p. 14).

\section{Considerações finais}

Se todas as noções partem das ações e são profundamente modificadas pelos níveis de conceituação alcançados pelos sujeitos, é preciso atentar para a maneira como isso influi na metodologia adotada pela $\mathrm{EF}$ ou por qualquer outra área do conhecimento. No caso específico da primeira, deve-se refletir acerca do que abrange o momento de troca entre os sujeitos que aprendem e ensinam os conhecimentos dessa área. Tudo que ocorre é parte de um todo que tem como cerne a interaçáo no modelo descrito anteriormente nos processos de tomada de consciência. Tudo interessa: gestos, palavras, pensamentos, disponibilidades, tensões, espaço físico, afeto, dentre outros. É preciso que o professor domine com aprofundamento e competência o seu próprio fazer, mas é fundamental que o articule entre outras perspectivas, para que, assim, todas as áreas de conhecimento se fortaleçam e, por consequência, uma compreensão mais adequada da realidade possa ser conquistada por estudantes e mestres. É importante 
tornar flexível não só a maneira de pensar, mas a organização da estrutura curricular da escola levando em conta essa concepção, e, dessa forma, permitir que o fluxo das relaçóes constituídas pelos estudantes e professores transite por diferentes momentos e espaços curriculares. São visíveis os progressos quando o estabelecimento de relações de cooperação e de troca de valores fazem parte do cotidiano pedagógico por serem buscados intencionalmente por todos em tudo que se faz, por mais simples que pareça: constituição dos horários, abertura para novas ideias e projetos, criação de momentos de escolha, sistemática de colaboração, trocas valorizadas entre estudantes de turmas diferentes e entre professores novos e antigos. Por ser essa uma característica da dinâmica do Projeto Amora - CAp/UFRGS, diferentes relações são possíveis: trabalhos interdisciplinares surgem, generalizações constituídas pelos estudantes e pelos professores se potencializam ao integrar por meio da ação e da reflexão com esquemas elaborados nos diferentes momentos curriculares que podem corroborar para aprendizagens significativas.

Os dados indicam a existência de uma complementaridade entre os processos de constituição de valores dos educadores e dos educandos. A realização de atividades interdisciplinares no contexto do Projeto Amora é favorecida quando se exerce intencionalmente a possibilidade de tornar mais flexível uma escala de valores entre mestres e aprendizes e quando há o firme propósito de qualificar o processo de construção de conhecimentos dos estudantes. Esse processo contribui para a constituição de um trabalho pedagógico organizado, levando-se em consideração objetos comuns entre diferentes áreas do conhecimento, o que possibilita a qualificação dos processos pedagógicos do Projeto Amora. Constata-se, também, a relevância e a participação significativa de aspectos essenciais do Método Clínico de Jean Piaget na prática docente. 


\section{Referências}

ARAÚJO, Karina de Toledo. Os jogos na educação física e a construção das estruturas lógicas do pensamento. Maringá: Universidade Estadual de Maringá, 2003. 100p. Dissertação (Mestrado em Educação), 2003.

BRACHT, Valter. Educação física e aprendizagem social. Porto Alegre: Magister, 1992.

BRACHT, Valter. A constituição das teorias pedagógicas da educação física. Campinas: Cadernos CEDES, v. 19, n. 48, $1999 \mathrm{~b}$.

CARRACEDO, Valquíria Aparecida; MACEDO, Lino de. Jogo carimbador: esquemas de resolução e importância educacional. In: Revista Paulista de Educação Física. São Paulo, v. 14, n. 1, p. 29-44, jan./jun. 2000.

DELVAL, Juan. Introdução do método clínico descobrindo o pensamento das crianças. Porto Alegre: Artmed, 2002.

FALZETTA, Ricardo. A educação física dá uma mãozinha. In: Revista Nova Escola On-line. São Paulo,1999. Disponível em: http://novaescola. abril.uol.com.br/ed/120_mar99/html/matematica.htm. Acesso em 16 de ago. 2005.

FARIAS, Stela Maris Vaucher. A gênese do espaço projetivo e as interações sociais nos jogos de regras e de construção. Porto Alegre: Universidade Federal do Rio Grande do Sul, 2006. 212p. Dissertação (Mestrado em Educação), Porto Alegre, 2006.

FOGAÇA, Orlando Mendes Júnior. A formação da noção de força corporal na criança: contribuições para a educação física. Marília: Universidade Estadual Paulista Julio de Mesquita Filho, 2009. 115p. Tese (Doutorado), Marília, 2009.

FONSECA, Denise Grosso da. Educação física: para dentro e para além do movimento. Porto Alegre: Mediação, 1999a.

FREIRE, João Batista. Educação de corpo inteiro: teoria e prática da educação física. 4 ed. São Paulo: Scipione, 1994.

FREIRE, João Batista. As relações entre o fazer e o compreender na prática da educação física. São Paulo: USP, 1982. 161p. Dissertação (Mestrado em Educação Física), São Paulo, 1982. 
FREIRE, João Batista. Pedagogia do futebol. 2. Ed. Campinas: Autores Associados, 2006.

FREIRE, João Batista. Oficinas do jogo: ensino, pesquisa e extensão. In: Revista Brasileira de Docência, Ensino e Pesquisa em Educação Física. Cristalina, v. 1, n. 1, p. 157-175, 2009.

FREIRE, João Batista. O sensível e o inteligível: novos olhares sobre o corpo. São Paulo: USP. 233p. Tese (Doutorado em Psicologia Educacional), 1991.

GONZÁLES, Fernando Jaime. Influência do nível de desenvolvimento cognitivo na tomada de decisão durante jogos motores de situação. In: Revista Movimento. Porto Alegre, ano V, n. 10, p. 3-14, 1999. Disponível em: http://seer.ufrgs.br/index.php/Movimento/issue/view/175/showToc. Acesso em: 20 de jan. 2011.

GONZÁLES, Fernando Jaime. Sistema de classificação de esportes com base nos critérios: cooperação, interação com o adversário, ambiente, desempenho comparado e objetivos táticos da ação. Lecturas educación física y deportes. Buenos Aires, v. 71, p. 1-8, 2004. Disponível em: www. efdeportes.com/efd71/esportes.htm. Acesso em: 20 de jan. 2011.

GONZALÉZ, Fernando; FRAGA, Alex Branco. Lições do rio grande: livro do aluno - caderno pedagógico destinado à 5a. 6a séries do ensino fundamental. Secretaria de Educação do Rio Grande do Sul, 2009.

INHELDER, Bärbel. $O$ desenrolar das descobertas da criança: um estudo sobre as microgêneses cognitivas. Tradução de Eunice Gruman. Porto Alegre: Artes Médicas, [1992] 1996.

LE BOULCH, Jean. Rumo a uma ciência do movimento humano. Porto Alegre: Artes Médicas, 1987.

LE BOULCH, Jean. O desenvolvimento psicomotor: do nascimento até 6 anos. Porto Alegre: Artes Médicas, 1986.

LISBOA, Adonis Marcos. A inteligência em jogo: estudo sobre a solução de problemas no contexto do jogo. Florianópolis, Universidade do Estado de Santa Catarina, 2005. 92p. Dissertação (Mestrado), Florianópolis, 2005.

MONTANGERO, Jaques; NAVILLE, Danielle Maurice. Piaget e a inteligência em evolução. ArtMed, 1998. 
PARLEBAS, Pierre. Elementos de sociología del deporte. Andalucia: Junta de Andalucia, 1988.

PIAGET, Jean. A representação do mundo na criança. Rio de Janeiro: Record, s/data.

PIAGET, Jean. Estudos sociológicos. Rio de Janeiro: Editora Forense, 1973.

PIAGET, Jean. A tomada de consciência. São Paulo: Edusp/Pioneira, 1977.

SALADINI, Ana Cláudia. A educação física e a tomada de consciência da ação motora da criança. Marília: Universidade Est. Paulista Júlio de Mesquita Filho, 2006. 224p. Tese (Doutorado em Educação) - Marília, 2006.

SOARES, Carmen Lúcia; TAFFAREL, Celi; VARJAL, Elizabeth; CASTELLANI, Lino; ESCOBAR, Michele Ortega; BRACHT, Valter. Metodologia do ensino da educação física. São Paulo: Cortez, 1992. (conhecido como COLETIVO DE AUTORES).

YIN, Robert. Estudo de caso. Tradução de Daniel Grassi. 3 ed. Porto Alegre: Bookman, 2005. 